\title{
Playing Cultures
}

\section{Introduction}

The genesis of this article is a series of observations that occurred at a marae, which are used here as a platform from which broader issues of certain aspects of Māori-Pākehā interactions can be explored and critiqued. The trajectory of biculturalism and its accompanying narrative - as a linear progression of mutual engagement between Māori and Pākehā - has been an accepted orthodoxy in this discourse for decades, with the extent, character, and form of engagement being among the principal points of focus for consideration. However, what is examined here is a radically different interpretation to this approach to biculturalism. The main reason for this is that much of the discourse around biculturalism bypasses the risks for indigenous cultural marginalisation that these narratives have the potential to cause. It is further argued here that there can be an element of racism within the practice of biculturalism that is not merely incidental, but rather functions as one of its central operating principles.

This work is necessarily impressionistic in the manner in which it tackles the issues under review. The aim here is not to be comprehensive, nor to question anyone's goodwill in the realm of biculturalism. Rather, it is to sift through some of the elements that comprise current iterations of Pākehā roles in bicultural interactions with Māori. One of the central themes that runs through this survey is the dimensions of power relationships and indigenous agency in these interactions, and their potential implications for interpreting aspects of

Melissa Derby (Ngāti Ranginui) is a PhD student and lecturer at the University of Canterbury.

Paul Moon is Professor of History at Auckland University of Technology. 
biculturalism. In particular, the possibility is explored here that beneath the goodwill and overtly positive intentions that typify Pākehā engagement with Te Ao Māori is an intricate web of cultural power relationships that unwittingly perpetuate a pattern of Pākehā cultural domination.

The starting point for this analysis is the notion, in the most general sense, of a Pākehā (or more specifically, Anglo-Saxon) cultural deficit existing in the country. What is proposed here is that one of the consequences of this is a particular (and predictable) set of reactions that are borne of a people experiencing this deficit. Of course, these are substantial simplifications, and are acknowledged here from the outset as such. However, the fact that they are generalisations does not necessarily diminish the insights they potentially offer in the area of New Zealand's distinct bicultural environment. From this point, the cultural customs of pōwhiri and pepeha are used as a starting point from which the intricate web of cultural integration, overlap, and encounter can begin to be disentangled. Consideration is given to the dynamic that exists between te reo Māori and English, where the incorporation of Māori words into the English lexicon is, in fact, playing a key role in destroying the indigenous language. The role of Kaupapa Māori research methodologies is also reviewed, as an example of neo-colonialism wrapped up as a concept that allegedly empowers Māori.

This work concludes by questioning many of the presumptions currently held about the utility of Pākehā engagement with Te Ao Māori. In particular, it sheds light on the ways in which what can superficially appear as favourable types of bicultural engagement have the potential, to the same extent, to entrench structures of Pākehā cultural domination. We deliberately do not offer any prescription for an alternative, but simply state these observations as a base from which further analyses can be carried out, and from which these interactions can be re-contextualised. 


\section{A Pākehā Cultural Deficit?}

The majority of Pākehā in New Zealand are of British descent. This is significant in the context of this work because Britain was one of the first nations to experience the Industrial Revolution, and therefore its population has endured the alienation from its traditional, rural-based culture for longer than any other ethnic group. Thomas Gray's Elegy Written in a Country Churchyard (1751) captured a sense of this traditional world in its twilight. A century later, the process of cultural alienation was well under way. Family structures, values, and ways of living changed dramatically. Certain sorts of knowledge were privileged while others were abandoned. Identity was less linked to ancestral land, and different social hierarchies and modes of mobility within those hierarchies emerged. The cumulative effect for many people in this newly-industrialised Britain was something close to an amputation from the traditional culture that had defined their Britishness in preceding generations. Rather, culture was being redefined by the forces of a modernised economy, with little deference to its preceding traditional incarnation.

This new, detached culture - a product of the modern rather than the traditional (and oriented accordingly) - became twicedetached when members of this modernised group migrated to New Zealand in the nineteenth and twentieth centuries. New Zealand became their 'home' - a disorienting notion for those peoples whose connections with the culture of their preindustrial ancestors was far more intimate. However, for this Pākehā group, the construct of a spatial 'home' generally tended to be confined to the principle that 'home is where the house is'. The affinity with the land, and the way in which it heaves with the pain and trauma of history, was largely absent. How could it be otherwise? After all, for many of this group, their only previous sense of 'home' was a place of occupation in another country, which was similarly culturally alienated from the intimacy of pre-industrial associations with place. Maybe all that was being traded in the process of Britons migrating to New 
Zealand in the nineteenth century in particular was climate and employment opportunities. Location was a means to other ends rather than a source of primordial identity.

A people with such a comparative cultural deficit were only ever likely to sink shallow roots in their new country of occupation. Even numerical dominance failed to compensate for the tenuous connection with the land and its past - a point made all the more vivid when put alongside the metaphysical ties that hapu and iwi have to the land - to their ipukarea.

So what attempts have been made by Pākehā to address their cultural deficit and their relatively weak connection with the whenua in New Zealand? There continues to be a range of responses, with one extreme emerging in the form of overt racism, in which notions of power (political, economic, social, and other forms) are emphasised, and function as a form of denial of any value of the indigenous world. That is, the practice of denouncing the Other as inferior on the basis of ethnicity is simply a means of avoiding having to confront the fact of living with a cultural deficit. There is also a corresponding tacit acknowledgment in such reponses that the indigenous group as a whole has what could be called (by contrast) a 'cultural surplus'. Racism in this specific context can serve as an unsophisticated coping mechanism, prompted to a degree by a partially subconscious awareness of the significance of the cultural surplus of the people at whom the racism is directed (and a parallel realisation of the cultural deficit possessed by those in that racist category). Such racism can also be compounded by fear, in which hostility towards and contempt for the Other is a projection of fear and of perceived cultural 'inadequacy'. Such overt racism is rare and becoming rarer, but at the same time is being displaced by other, potentially more insidious forms which are the main focus of this work. The nature of these other forms of racism are subtle in their manifestations, and prone to misinterpretation. Moreover, paradoxically, these other expressions of racism can sometimes 
appear in forms that superficially are judged to be beneficial to the agenda of biculturalism.

\section{Cultural Encounters}

One of the purposes of this article is to survey categories of activity that tend to be commonly classified as expressions of 'biculturalism', 'indigenous-orientation', 'power-sharing' and 'cultural-inclusion', and subject them to scrutiny to reveal undercurrents that potentially subvert these stated bicultural aims. In order to assist with this analysis, various case-studies are drawn on, which serve to illustrate the central themes highlighted in this work.

Consideration of the cultural significance and contemporary use of pōwhiri, for example, provides some insight into the discrepancies between overt and covert power relations, and the implications of Pākehā cultural mobility in relation to Māori culture. Pōwhiri can be defined in general terms as a ritual of encounter or, more appropriately perhaps in the context of this work, as a 'welcoming ceremony'. Traditionally, pōwhiri were comprised of complex and intricate connections to sacred aspects of Māori culture. Deities, particularly Tūmatauenga (god of war) and Rongo (god of peace), were awakened during pōwhiri. Forces related to cultural concepts such as tapu and noa were evoked, references to the afterlife were abundant, and shared whakapapa aided the two parties in establishing cordial relations. Pōwhiri served a very practical and necessary diplomatic purpose - to discover a visiting party's intentions, and to determine if a group was friend or foe.

In recent years, the desire by some Pākehā to be what they regard as 'culturally appropriate' has resulted in a proliferation of pōwhiri, particularly across the state sector, where this ancient and sacred ritual is frequently used to welcome visitors to schools, workplaces, and various public events. Typically, the order of business follows an increasingly familiar template, where proceedings commence with a pōwhiri (or, at times, a 
mihi whakatau) - hopefully, one that is short enough so as to not distract from the 'real' work to be done - followed by a cup of tea and some food before the parties are free to turn to the main purpose of the encounter. Overtly, the contemporary resuscitation of pōwhiri is seen to be contributing to a wellintentioned societal agenda of biculturalism - Pākehā can thus demonstrate that they are becoming more culturally responsive, and Māori are being included in an ostensibly meaningful way. The appendage of Māori culture in what is essentially a monocultural Pākehā New Zealand satisfies those who believe that incrementalism is the way forward - that with every pōwhiri, Māori culture is somehow gradually supplanting Pākehā culture, or at the very least, establishing a presence in the dominant culture. Such acts are seen by some as a coup, and by others as a first step towards even greater levels of biculturalism. The rationale in both cases rests with the notion that by increasing the prevalence of pōwhiri - and the visibility of Māori culture and language in general - eventually Te Ao Māori will be restored to its rightful place as the dominant culture in the country. However, the notion of incrementalism is, in fact, subversive, anti-cultural, and destructive, and it contributes to the consumption and repackaging of Māori culture by Pākehā to a form that is palatable and acceptable to the coloniser. Māori culture is diluted and distorted in the process, while the Pākeha position of power becomes more concentrated.

Ultimately, the frequency with which pōwhiri are performed weakens its complex meaning and cultural significance. For example, if the historical purpose of pōwhiri was to establish the intentions of a visiting party, this purpose is necessarily undermined in contemporary re-enactments of the ritual when the identity of the visiting party and their objectives are already known.

Furthermore, what happens to concepts such as tapu and noa, the deities, and connections to spiritual and metaphysical realms when pōwhiri are so often relegated to a choreographed 
cultural act constrained by the meeting's agenda (of which they are little more than the ceremonial part)? With every display of powwhiri, it would seem that the substantial cultural significance of the ritual diminishes. Meanwhile, the contemporary performance of pōwhiri serves to enhance a Pākehā position of power. The inclusion of pōwhiri is essentially sanctioned by Pākehā, and occur within a Pākehā-determined, Pākehā-driven framework - one in which Pākehā are creating space for Māori cultural rituals but where such rituals do not detract from the 'real work to be done' - nor do they threaten the Pākehā position of dominance within that space.

So why are pōwhiri consistently performed in such contexts, to the point where they have become an almost expected item on an agenda? Perhaps these displays provide a glimpse into an traditional world - a world that no longer exists but one that can be viewed through the lens of a modern incarnation that is made out to have primordial origins. Perhaps they serve a moral purpose, where Pākehā can atone for their self-perceived colonial sins by giving the appearance of relinquishing some of their power and cultural dominance to Māori. Or maybe there is an element of selfishness among Pākehā, who are eager to experience the depth and richness of Māori culture in order to fill the void gouged out by their own sense of cultural deficit. In this instance, pōwhiri provide an emotive and inclusive cultural encounter that may, in fact, serve to strengthen Pākehā identity - after all, this sacred and inherently Māori ritual is fast becoming a shared component of our national identity, and contributes to the notion of what it means to be a New Zealander'. With this in mind, is Māori culture becoming a 'performance culture', where, ultimately, the display of pōwhiri can only be seen as giving an 'indigenous flavour' to otherwise inherently Pākehā encounters? This can serve as an act of racism in itself, insofar as aspects of indigenous culture become relegated to superficial, tick-box performances that are sanctioned by Pākehā, and operate within an entirely Pākehā framework. 
Similar themes and power dynamics are evident in instances where Pākehā deliver a pepeha. Reduced to a pithy definition, a pepeha is an introduction a person gives to establish their identity through associating themselves with a location (and all the cultural implications of being from that place). However, the cultural space which pepeha occupy is far more intricate, and, like pōwhiri, intersects with several overlapping cultural, political, and metaphysical realms.

For Māori, delivering one's pepeha establishes deep cultural connections to the whenua, maunga, and various other geographical features, which in turn have intricate spiritual, historical, and genealogical connotations. To deliver a pepeha is to locate oneself in the entirety of one's culture and web of existence, and to reaffirm the connections with creation narratives and the mauri of all things. And on the other side of this process, the audience - in listening to someone's pepeha learns about that person, their place in the wider social and cultural milieu, and importantly, can identify points of commonality, or at least familiarity. Reference to mutuallyknown geographic features (which expand as the range of features one refers to extends) increases the likelihood of these connections being made.

As an act of 'cultural appropriateness', it has become increasingly common for Pākehā to recite their pepeha in certain settings of encounter. Some of the feedback received from enquiries undertaken for this paper on these recitations is that these deliveries of pepeha can be 'awkward', 'unnatural', 'apologetic', 'culturalist', 'appropriating', 'bizarre', and 'fraudulent'. The question then arises as to what is the purpose of pepeha, and what other dynamics are at play.

On the face of it, when delivering a pepeha, it might seem as if Pākehā are connecting with and embracing Māori culture - and by doing so, are attempting to locate themselves in a bicultural paradigm. They are seen to be stepping outside their own cultural practices to adopt those of country's indigenous population. Often, Māori applaud these attempts - on the 
surface at least - hailing these Pākehā as the 'good ones' who are committed to a bicultural New Zealand, while also perhaps seeing this act as contributing incrementally to the resurgence of Māori cultural imperatives. Pākehā delivering pepeha can also give the superficial impression of a shift in the balance of cultural power in the country, in which after two centuries of colonisation, the implicit Pākehā cultural dominance is giving way to something slightly less one-sided, and in this is the hope that the process will continue and lead to some realignment of cultural priorities in the country.

However, scratch the surface a little and there appears to be some less-encouraging dimensions to this sort of reasonably common cultural mimicry, which can be summarised in a series of related questions: what messages are conveyed about the option to exercise cultural power when Pākehā maintain their own cultural identity, but simultaneously (and temporarily) adopt - or usurp - aspects of Māori culture? When the process of adoption has expired, and Pākehā revert fully to their own cultural group and practices, where does the power really lie in this interaction? The cultural agency seems to be in the hands of Pākehā in such cases. Further to this, what cultural deficit are Pākehā attempting to fill, and what connection to place are they attempting to forge (literally as well as figuratively), where for Māori, home is where the heart is but for Pākehā home is where the house is? What happens to pepeha in this instance, when such a culturally-grounded, rich and significant act is so easily appropriated and consequently diluted? It would seem that such performances do not end up playing an affirmative role in the revitalisation of Māori culture. Instead, they highlight the power of Pākehā culture to dabble with Māori cultural practices and experiences with no impact whatsoever on their own culture. This is not so much a show of cultural strength, but of power (a position of power that is ironically consolidated by such acts). 


\section{Te Reo}

Similar processes and concepts exist in the use of te reo by Pākehā, but with the added element that the consequences are potentially far more long-reaching and harmful. Many people have celebrated the fact that Māori words are appearing with increasing frequency in New Zealand English, as spoken by Pākehā. This must be a good thing, it is believed, because in such small increments, te reo is being advanced, and to that extent, its prospects for survival are improving. But the same issues of cultural power are at work here, with something that outwardly appears to be 'culturally appropriate' functioning in a way that is fundamentally counterproductive.

When words from te reo are incorporated into spoken English, what is really happening? Firstly, English, as a cultural entity, is exercising agency because it is the lexicon that is doing the incorporating. Secondly, English becomes that much stronger through broadening its vocabulary by incorporating additional words (in this case, from te reo). But most importantly, it is the consideration of what happens to those words from te reo when they are incorporated into English that has a bearing on the power relationship between the two cultures. Firstly, words appropriated from te reo are culturally and grammatically decontextualized, and their idiomatic force is drained from them. But secondly, and much more significantly, far from enhancing the health of te reo, such a process bolsters English at the expense of te reo. As an example, there are dozens of Hindi and Urdu words used in New Zealand English (such as bangle, bungalow, cot, dinghy, jungle, loot, pyjamas, veranda, and so forth). Does their use enhance the Hindi or Urdu languages in New Zealand? No. Does their use advance those respective cultures in New Zealand? No. Over time, do people using these words become more aware of their etymology or cultural significance? No. In fact, by English incorporating words from te reo, it is not just appropriating those words, but anglicising them. The irony in this is that what is intuitively seen as something positive (the addition of 
Māori words in the New Zealand English lexicon) is quite the opposite: it is one of the most extreme and effective forms of cultural appropriation (and possibly even destruction). It is extreme because by normalising those words in English, it is necessarily depriving them of their mauri, of their idiomatic force, of their whakapapa, and thus allows them to be devoured by the world's most predatory language. And if there is any doubt in this, try finding any language that has ever been revived by having some of its vocabulary incorporated by another, much stronger language.

\section{'Engagement'}

A consideration of Pākehā engagement with Māori communities, particularly in the context of activities associated with research, brings to light interactions that serve to illustrate further the central themes addressed in this work. More specifically, an exploration of the power dynamics at play in research that employs a Kaupapa Māori approach is particularly revealing. Essentially, Kaupapa Māori research is a tool developed by Māori researchers with clear cultural and political intentions. It has two distinct purposes - firstly, it establishes the ideological framework in which to locate research, and secondly, it determines culturally responsive methods for engagement, data collection, and analysis. An overarching aim of Kaupapa Māori research is to contribute to broader goals associated with self-determination, transformation, and a renaissance of Māori culture. This approach to research emerged from a wider Kaupapa Māori movement that has imperatives such as tino rangatiratanga and mana motuhake at its core. It is important to acknowledge that Kaupapa Māori research has had a profound impact on the research landscape in New Zealand. It has transformed the ways in which research is conducted and analysed, ensuring researchers are accountable to the communities alongside whom they are working. It also stresses the importance of being 'cognisant' of cultural and socio- 
historical contexts, and to that extent, shapes and frames the ensuing findings to accord with the prescribed ideological aims of the approach.

Kaupapa Māori research is informed by a set of culturallylocated ethical guidelines, which assist researchers on means of 'authentic' and appropriate engagement with Māori communities. It is therefore necessarily reliant on a set of assumptions about Māori histories, experiences, and cultural 'realities', which are complex, multiple, fluid, and constantly evolving, but which in a Kaupapa Māori model are reduced to a uniform, monolithic cultural construct - one bereft of political, social, and cultural plurality. It therefore simultaneously applies to all Māori and possibly no Māori.

The question that emerges from a dispassionate review of the Kaupapa Māori ideology is what generalisations are being made by a 'one size fits all' approach to research about a singular Māori 'reality', a homogenous Māori worldview, and uniform Māori cultural experiences? Then, as a consequence of such generalisations, what conclusions might be drawn if researchers encounter communities or individuals whose realities do not align with those espoused by Kaupapa Māori contentions? The application of the Kaupapa Māori research approach therefore requires a suspension of a degree of reality, and the maintenance of a construct of Māoriness that is at least as much ideological as cultural in its basis, and that implies a uniformity that does not and never has existed in practice. Taken to its logical conclusion, Kaupapa Māori is a model of recolonisation - one which imposes neo-Marxist constructs and reductions of cultures and communities onto Te Ao Māori. The validity (or otherwise) of research conducted under the ideology of Kaupapa Māori is unavoidably affected by these neo-colonial constructs.

In his 1969 book Custer Died for Your Sins: An Indian Manifesto, Vine Deloria asks: 'After all, who can conceive of a food-gathering, berry-picking, semi-nomadic, fire-worshiping, high-plains and-mountain-dwelling, horse-riding, canoe-toting, 
bead-using, pottery-making, ribbon-coveting, wickiupsheltered people....as real?' This is perhaps an exaggerated example, but this hyperbolic approach serves to highlight the danger in assumptions about singular realities, which, rather than strengthening a group, might in fact unwittingly contribute to its invisibility or distortion. In considering this, what constraints might assumptions associated with Kaupapa Māori research place on the presence, position, and power of Māori communities? Surely, there is a risk that if Māori communities are thus defined, delineated, and demarcated, their power and ability to exercise tino rangatiratanga and mana motuhake becomes restricted, and might flourish only within the parameters set by these (essentially colonising) assumptions. For those communities who are contained within these conceptual restraints, are they still Māori, or are they Māori in the image of Foucault-inspired notions of indigeneity?

Increasingly, Kaupapa Māori research approaches are being adopted by Pākehā, who are conducting research involving Māori participants. It is common practice in these instances to involve Māori researchers, who, in addition to advancing the research in question, might also hold positions of power, for example on advisory boards, to ensure the research is conducted in a culturally appropriate and responsive manner. There may also be an expectation by Pākehā researchers that relationships with research communities will be fostered and maintained, or existing relationships capitalised on, through adhering to the Kaupapa Māori approach. And so the foundations of a research relationship are established - one that is determined by Kaupapa Māori imperatives, infused with the overlying appearance of Pākehā goodwill (often genuinely felt and expressed), and where Māori researchers and communities appear to be in a position of dominance, while Pākehā are conversely apparently relegated to a state of cultural submission.

So much for first impressions. A deeper reflection of the underlying power dynamics in these relationships may reveal a 
shift in power that is concealed by the appearance of the relationship on the surface. Essentially, Pākehā researchers are largely setting aside their cultural practices and viewpoints in order to engage with Māori in a manner that is culturally responsive to this stereotypical construct of Māori. If Pākehā can adopt aspects of Māori culture in order to engage effectively and, apparently 'authentically' with Māori, where does the power really lie in such an act? Surely it is evidence of Pākehā dominance in that Pākehā are able to adopt Māori practices with no impact on their own position, presence, and, ultimately, power. Further to this, what messages are being conveyed about the strength of Māori culture and the power and agency (or perhaps lack thereof) of Māori communities if it is insinuated that Pākehā must engage with Māori in this way? It would seem that this form of cultural oscillation implies that Māori communities may be harmed in some way by anything that is not reflective of and aligned to the ideals articulated by Kaupapa Māori research, and therefore need to be wrapped in a sort of cultural cotton wool. This view is profoundly negative, and positions Māori as 'vulnerable', and therefore in need of special protection. The Kaupapa Māori approach has echoes of the 'fatal impact' theories that reached their high-point decades ago, in which Pākehā intervention in Māori society strengthened the former and undermined the latter. Pākehā had the power to intervene, and to shape the form of that intervention, while Māori exercised barely any agency whatsoever, and were thus reduced to being hapless recipients of this external involvement. Overall, Kaupapa Māori methods ironically can end up affirming Pākehā cultural dominance, while simultaneously projecting a non-existent, uniform, and culturally contrived model of what constitutes being Māori.

\section{Cultural Mobility}

One of the central themes that has emerged in this work is that of cultural mobility. In the context of this paper, it relates to the 
possibility of the dominant cultural group entering into the cultural space of the minority, indigenous group, and undertaking what in some cases can be interpreted as acts of cultural mimicry. There are two aspects of this process that are relevant to some of the ideas discussed in this work: the sanctioning of cultural mobility, and the issue of cultural power associated with it.

When people from a majority or dominant culture enter the world of the minority indigenous culture, they generally seem to be doing so with good intentions - to 'support' the culture, as it is sometimes explained. Moreover, this entry into the world of another culture is typically sanctioned by some of the members of that indigenous culture on the basis that the 'support' offered is based on genuine goodwill. If, however, someone from the majority, dominant culture entered the world of the minority indigenous culture with different motives - say, for example, cultural appropriation - then they would not be welcomed, and rightly so.

What is significant about these forms of cultural mobility is that the determination of their permissibility by the indigenous culture is based on the intent of the dominant, majority culture. The reason this is significant is that the emphasis is clearly on the motive of the cultural interloper rather than the fact of their interpolation. While this is understandable at a superficial level, it necessarily occurs at the expense of consideration of the ways in which one culture exercises mobility in the space of another culture. This has connotations in terms of the actions that are associated with a dominant culture. Typically, it is the dominant culture that engages in such mobility, in ways, and times, and at levels of its choosing. The minority indigenous culture is the recipient of these interpolations, and decides only on how to manage them rather than the larger issues of the fact of their occurrence.

The ways in which the majority culture exercises its mobility in such spaces might seem supportive of the minority indigenous culture, but it is actually fundamentally subversive. 
It is a reminder of the supremacy of the majority culture, precisely because such interpolative acts are those of dominant and domineering cultures. In addition, the way in which the minority, indigenous culture so often welcomes this 'support' is a concession that cultural solidarity with the majority culture is somehow beneficial, even though historically at least, the growth of one has often occurred at the expense of the other.

There is also the issue of the limits associated with the dominant cultural group entering the cultural space of the minority, indigenous group, with a view to 'embracing' the culture of the latter. While it might outwardly seem like such actions will enhance the culture of the minority indigenous group, it is the dominant group that is doing the metaphorical enhancing, and furthermore, it is the dominant group which makes the decision about the extent of their involvement in the minority indigenous culture, the duration of this involvement, and the purpose of it.

\section{Conclusion}

If power in a society is determined by certain variables - wealth, health, longevity, educational attainment, lower than average imprisonment rates, lower beneficiary rates, higher homeownership rates, political representation, and so forth - then on these measures, it would be reasonable to assert that in general, Pākehā have more power in New Zealand than Māori. This being the case, the question emerges as to whose benefit is being served by members of a more powerful cultural group mimicking, appropriating, embracing, or examining elements of the culture of the less powerful group? And as a corollary of this question, is the culturally-dominant group's position diminished or enhanced by the process? The same question can be asked in relation to the position of the minority group. Empirically, it would seem that the terms of involvement in and with the minority culture are prescribed by the dominant culture, which benefits from this involvement not only by 
consolidating its position as the dominant group but also by usurping elements of the culture of the minority group in order to fill the void left by its own cultural deficit. Essentially, Māori do not exercise control over Pākehā efforts at 'embracing' Māori culture. Therefore, the agency and power rests with those doing the embracing, and their position of power is consolidated by the repetition of such acts. Moreover, because Pākehā are numerically dominant, Māori are more likely to be reliant on Pākehā to commit to an agenda of biculturalism and powersharing, and to provide environments of cultural inclusion, which further undermines Māori power and agency. Ultimately, the prevalence with which we see Māori cultural practices appear at a wider societal level is sanctioned by Pākehā, and Māori culture is given space within broader, inherently Pākehā frameworks and environments.

If biculturalism was no longer the 'agenda du jour' for Pākehā, what implications would this have for Māori culture? On the one hand, we may see fewer overt expressions of Māori culture in wider society - pōwhiri may cease to be part of state sector encounters, Pākehā would no longer deliver pepeha or pepper their sentences with Māori words, and Pākehā researchers may abandon Kaupapa Māori approaches in their research practice. Ostensibly, this may be viewed as regressive, with the incremental gains in the Māori 'cultural renaissance' achieved over decades turning out to be for nothing. Essentially, those Pākehā practices, which on the surface appear to be strengthening Māori culture and agency are, in fact, subversive in nature, damaging the very things these acts purport to strengthen, perhaps to the point of eventual destruction or consumption by the more powerful and dominant group. Therefore, on closer inspection, an abandonment of an agenda of biculturalism may, paradoxically, serve to strengthen Māori culture, to the extent that the culture will be devoid of Pākehā interference, and instead will be free to evolve, respond, and engage, as all cultures do, under the influence of contemporary Māori experiences and realities. 
It was stated at the outset that the intention of this work was not to offer any concrete suggestions for an alternative to biculturalism, but rather to go beneath the dynamic that exists on the surface of Māori-Pākehā cultural interactions, delving into the underlying power relationships to emerge with a different perspective on what is really at play.

This exploration of Māori-Pākehā engagement considers the implications of Pākehā cultural mobility, cultural appropriation, and cultural mimicry of Māori culture, in a way that demonstrates entrenched issues of power, agency, and cultural domination. The very things that are conventionally depicted as strengthening Māori culture and positions of power in the bicultural arena are potentially threatening Māori cultural rigour, undermining Māori agency, curbing the extent of Māori power, and, ultimately, contributing to a process of indigenous cultural assimilation and marginalisation - while simultaneously perpetuating a Pākehā position of power and cultural domination. 